\title{
Azorella compacta methanolic extract induces apoptosis via activation of mitogen-activated protein kinase
}

\author{
MIN HEE SUNG ${ }^{1,2}$, OK-KYOUNG KWON ${ }^{1,3}$, SEI-RYANG OH ${ }^{1}$, JOONGKU LEE ${ }^{4}$, \\ SANG-HONG PARK ${ }^{4,5}$, SANG BAE HAN ${ }^{2}$ and KYUNG-SEOP AHN ${ }^{1}$
}

\author{
${ }^{1}$ Natural Medicine Research Center, Korea Research Institute of Bioscience and Biotechnology, Cheongju, \\ Chungbuk 363-883; ${ }^{2}$ College of Pharmacy, Chungbuk National University, Cheongju, Chungbuk 361-763; \\ ${ }^{3}$ College of Pharmacy, Chungnam National University, Daejeon 305-764; ${ }^{4}$ International Biological Material Research Center, \\ Korea Research Institute of Bioscience and Biotechnology, Daejeon 305-806; ${ }^{5}$ Division of Plant Management, \\ National Institute of Ecology, Secheon-gun, Chungnam 325-813, Republic of Korea
}

Received October 15, 2014; Accepted June 30, 2015

DOI: $10.3892 / \mathrm{mmr} .2015 .4317$

\begin{abstract}
Azorella compacta Phil. (AC) is an alpine medicinal plant used traditionally for antibacterial treatment. Recent studies have revealed that this plant also has anti-diabetic effects, but that it is toxic. The present study investigated the underlying mechanisms of action of $\mathrm{AC}$ extract against human leukemia HL60 cells. Apoptosis induction was measured by MTT assay, fluorescence microscopy, DNA fragmentation assay, flow cytometric analysis, reverse transcription quantitative polymerase chain reaction and western blot analyses. It was found that $\mathrm{AC}$ extract inhibited the growth of HL60 and other cancer cell lines in a dose-dependent manner. The cytotoxic effects of AC extract on HL60 cells were associated with apoptosis characterized by DNA fragmentation and dose-dependent increases in Annexin V-positive cells, as determined by flow cytometric analysis. AC-extract-induced apoptosis was accompanied by activated/cleaved caspase-3, caspase- 9 and poly(adenosine diphosphate-ribose) polymerase (PARP). The increases in apoptosis were also associated with decreases of the apoptosis-inhibitor B-cell lymphoma 2 (Bcl-2), upregulation of pro-apoptotic Bcl-2-associated X (Bax) protein and downregulation of anti-apoptotic $\mathrm{Bcl}$ extra large protein. Furthermore, western blot analysis of mitogen-activated protein kinase (MAPK)-associated proteins indicated that treatment with AC extract increased the levels of c-Jun $\mathrm{N}$-terminal kinase, extracellular signal-regulated kinase and p38. In addition, the expression of Bax and cleaved PARP
\end{abstract}

Correspondence to: Dr Kyung-Seop Ahn, Natural Medicine Research Center, Korea Research Institute of Bioscience and Biotechnology, 30 Yeongudanji-ro, Cheongju, Chungbuk 363-883, Republic of Korea

E-mail:ksahn@kribb.re.kr

Key words: Azorella compacta, apoptosis, intrinsic pathway, mitogen-activated protein kinase, HL60 was blocked when AC treatment was performed in the presence of MAPK inhibitors. It was therefore concluded that AC induced apoptosis in human leukemia HL60 cells via an intrinsic pathway controlled through MAPK-associated signaling.

\section{Introduction}

Apoptosis, an active, morphologically distinct form of programmed cell death, has a fundamental role in the normal development and differentiation of multicellular organogenesis, in the control of cell proliferation, in development, and in the pathogenesis of various diseases $(1,2)$. Apoptosis is also characterized by cell shrinkage, blebbing of membranes, nuclear condensation and DNA fragmentation (3-5). In addition, induction of apoptotic cell death is an important mechanism of numerous anti-cancer drugs (6). The intrinsic apoptotic pathway is triggered by a range of physical and chemical stimuli causing mitochondrial dysfunction $(7,8)$. The initiation of the apoptotic cascades leads to the activation of caspase- 9 and subsequent activation of effector caspases, such as caspase-3, which in turn cleaves several specific substrates, including poly(ADP-ribose) polymerase (PARP), as well as architectural components of the cell, which eventually leads to apoptosis (9). Proteins of the B-cell lymphoma 2 (Bcl-2) family serve as critical regulators of mitochondrial apoptosis, functioning as either inhibitors or promoters of cell death. Bcl-2 and Bcl extra large protein $\left(\mathrm{Bcl}-\mathrm{X}_{\mathrm{L}}\right)$ inhibit apoptosis by blocking the release of cytochrome $\mathrm{C}$ from mitochondria through prevention of channel formation, which is mediated by $\mathrm{Bcl}-2$-associated $\mathrm{X}$ protein (Bax) $(10,11)$. Mitogen-activated protein kinases (MAPKs), including c-Jun N-terminal kinases (JNK), extracellular signal-regulated kinases (ERK) and p38/MAPK, are activated in response to various stimuli. Subsequent to their activation, they participate in a variety of signaling pathways regulating diverse cellular processes, including cell growth, differentiation and stress responses. Activation of MAPKs is therefore closely associated with stress stimuli-induced apoptosis (12-14). 
It was previously reported that Azorella compacta Phil. (AC), a green, compact, resinous cushion shrub of the Apiaceae family growing in the high Andes of southern Peru and Bolivia, northeastern Chile and northwestern Argentina, contained mulinane and azorellane diterpenoids $(15,16)$. In Chilean folk medicine, AC, together with other Azorella and Laretia species (collectively known as 'llareta') is used for the treatment of a variety of ailments (15). Historical records indicated that $\mathrm{AC}$ has been used to treat the common cold and pain, to reduce blood sugar, and also as an ointment to treat dermatological disorders. AC presents a valuable source of mulinane and azorellane diterpenoids $(15,17)$. AC has also been traditionally used to treat colds, asthma and bronchitis, as well as conditions whose main symptoms include inflammation and pain. Studies on AC have demonstrated anti-bacterial (18) and anti-plasmodial properties (19). However, to the best of our knowledge, no scientific studies are available on their cytotoxicity-based anti-cancer effects.

The present study was the first, to the best of our knowledge, explore the potency of AC extract to induce apoptosis of human leukemia HL60 cells and to elucidate its underlying mechanisms of action. The apoptotic effects of AC extract were assessed by examining the caspase-dependent pathway involving the loss of mitochondrial membrane permeability, the release of cytochrome $c$ and the activation of the Bcl-2 family of proteins. In addition, the involvement of MAPK-dependent signaling was assessed using MAPK inhibitors.

\section{Materials and methods}

Chemicals. The following reagents and kits were used in the present study: Iscove's modified Dulbecco's medium (IMDM), fetal bovine serum (FBS) (Gibco-BRL, Carlsbad, CA, USA), Dulbecco's modified Eagle's medium (DMEM), RPMI-1640, phosphate-buffered saline (PBS) (Hyclone, Logan, UT, USA), MTT (Amresco, Solon, OH, USA), trypan blue, Hoechst 33342, caspase-3 substrate acetyl-Asp-Glu-Val -Asp-7-amino-4-trifluoromethyl coumarin (Ac-DEVD-AFC) (Invitrogen Life Technologies, Carlsbad, CA, USA), dimethyl sulfoxide (DMSO), adriamycin, 2',7'-dichlorodihydrofluorescein diacetate (DCFH-DA), formaldehyde (Sigma-Aldrich, St. Louis, MO, USA), agarose, 5X TBE buffer (Bioneer Corp., Daejeon, Korea), apoptotic DNA ladder kit (BioVision, San Diego, CA, USA), Annexin V-fluorescein isothiocyanate (FITC)/propidium iodide (PI) kit (BD Biosciences, Franklin Lakes, NJ, USA), Omniscript RT kit (Qiagen, Hilden, Germany), polymerase chain reaction (PCR) premix (Promega Corp., Madison, WI, USA), TRIzol reagent, enhanced chemiluminescence (ECL) reagent (Thermo Fisher Scientific, Waltham, MA, USA) and polyvinylidene difluoride (PVDF) membranes (Merck-Millipore, Billerica, MA, USA), PD98059, SP600125 and SB203580 (Santa Cruz Biotechnology, Inc., Dallas, TX, USA).

Cell line and cell culture. The cell lines HepG2, MCF7, HT1080, A549, SNU-1 and HL60 were procured from the American Type Culture Collection (Manassas, VA, USA). HepG2, MCF7 and HT1080 cells were routinely cultured in DMEM supplemented with $10 \%$ FBS. SNU-1 cells were routinely cultured in RPMI-1640 supplemented with 10\% FBS.
HL60 cells were routinely cultured in IMDM supplemented with $20 \% \mathrm{FBS}$ in a humidified incubator maintaining $5 \% \mathrm{CO}_{2}$ at $37^{\circ} \mathrm{C}$. For experimental purposes, all cells were harvested by centrifugation for $5 \mathrm{~min}$ at $250 \mathrm{xg}$.

Preparation of AC extract. A methanolic extract of AC was obtained from the International Biological Material Research Center (Korea Research Institute of Bioscience and Biotechnology, Daejeon, Korea). To produce the extracted solid (20.05 g), ground AC seeds (147 g) were treated with methanol and sonicated several times for three days. The dried extract was dissolved in $20 \mathrm{mg} / \mathrm{ml}$ DMSO to prepare a stock solution, which was then diluted with PBS.

MTT assay. In the MTT assay, MTT is metabolized into a colored formazan precipitate by mitochondrial dehydrogenases present only in viable cells, which is utilized to quantify the number of viable cells. Cells were seeded into 96-well plates $\left(2.5 \times 10^{4}\right.$ cells/well in $200 \mu \mathrm{l}$ medium). AC extract was added to the cells in serial concentrations $(0-100 \mu \mathrm{g} / \mathrm{ml})$ in quadruplets and incubated for $20 \mathrm{~h}$. Adriamycin $(2 \mu \mathrm{g} / \mathrm{ml})$ was used as a positive reference drug. Subsequent to incubation with the drugs, $10 \mu \mathrm{l}$ MTT solution (5 $\mathrm{mg} / \mathrm{ml}$ in PBS) was added to each well, followed by incubation for $4 \mathrm{~h}$. The plates were then centrifuged at $250 \mathrm{xg}$ for $10 \mathrm{~min}$ and the medium was removed by aspiration. Finally, the formazan crystals were dissolved in $100 \mu \mathrm{l}$ DMSO and the absorbance at 570 and $630 \mathrm{~nm}$ was measured using a 96-well-plate reader (VersaMax, Molecular Devices, Sunnyvale CA, USA). The inhibitory effect of the $\mathrm{AC}$ extract on cell growth was expressed as the percentage of viable cells, with the vehicle-treated cells considered $100 \%$ viable.

Hoechst 33342 staining. The morphology of the HL60 cells exposed to AC extract was first observed under an inverted microscope. HL60 cells were seeded into six-well plates $\left(2.5 \times 10^{5}\right.$ cells $/$ well in $1 \mathrm{ml}$ medium). After treatment with $\mathrm{AC}$ extract for $24 \mathrm{~h}$ at $0,5,10$ and $20 \mu \mathrm{g} / \mathrm{ml}$, the cells were harvested, washed in ice-cold PBS and fixed with $4 \%$ formaldehyde in PBS for $15 \mathrm{~min}$ at room temperature. The fixed cells were washed with PBS and stained with Hoechst 33342 solution $(10 \mu \mathrm{g} / \mathrm{ml})$ for $20 \mathrm{~min}$ at room temperature in the dark. The cells were then washed two times with PBS. Finally, they were observed under a fluorescence microscope and images were captured (Eclipse Ti-U; Nikon, Tokyo, Japan).

DNA fragmentation assay. Apoptosis was assessed by means of electrophoresis of genomic DNA extracted from HL60 cells treated with AC as described previously (20), with certain modifications. Briefly, HL60 cells $\left(1 \times 10^{6}\right.$ cells/well in $1 \mathrm{ml}$ medium) were treated with various concentrations of $\mathrm{AC}$ extract $(0,5,10$ and $20 \mu \mathrm{g} / \mathrm{ml})$ for $24 \mathrm{~h}$. Subsequently, the cells were harvested and washed in ice-cold PBS. The DNA was harvested using an Apoptotic DNA ladder kit (BioVision, San Diego, CA, USA) following the manufacturer's instructions, according to which the total DNA was analyzed using $1.5 \%$ agarose gel electrophoresis.

Annexin V/PI staining and flow cytometric analysis. Phosphatidylserine (PS) exposed on the outer mitochondrial 


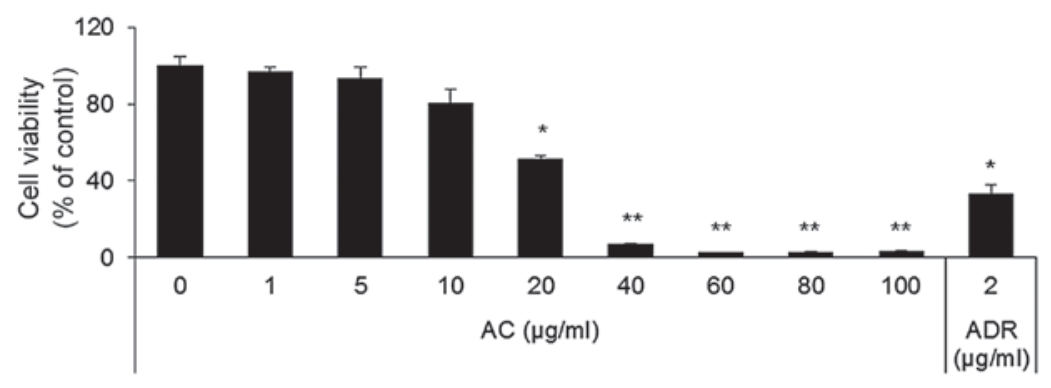

Figure 1. MTT assay showing the effect of AC extract on HL60-cell viability. HL60 cells were cultured in the absence and presence of AC extract (1-100 $\mu \mathrm{g} / \mathrm{ml})$ for $24 \mathrm{~h}$, and the cell growth inhibition effect were determined by MTT assay. Values are expressed as the mean \pm standard deviation of three independent experiments. ${ }^{*} \mathrm{P}<0.05 ;{ }^{* *} \mathrm{P}<0.01$ vs. untreated cells. ADR, adriamycin; AC, Azorella compacta.

membrane of the apoptotic cells was determined by an Annexin V-FITC apoptosis detection kit (BD Biosciences), as per the manufacturer's instructions. Briefly, following treatment with AC extract for $24 \mathrm{~h}$, cells were harvested by centrifugation ( $250 \mathrm{x} \mathrm{g}, 5 \mathrm{~min}$ ), washed twice with ice-cold PBS and re-suspended in binding buffer at a density of $1 \times 10^{6}$ cells/ml. Next, $5 \mu 1$ Annexin V-FITC and $5 \mu 1$ PI were added to $100 \mu \mathrm{l}$ cell suspension, which was then incubated in the dark for $15 \mathrm{~min}$. Finally, $400 \mu \mathrm{l}$ binding buffer was added to the cell suspension. Cells were then analyzed using a flow cytometer (BD Biosciences, San Diego, CA, USA). The data were analyzed with CellQuest software (BD Biosciences).

Measurement of intracellular reactive oxygen species (ROS). First, samples of HL60 cells were treated with AC extract as described above. The production of reactive oxygen species was then measured using the membrane-permeable dye DCFH-DA. The dye was added to cells cultured in six-well plates $\left(2.5 \times 10^{4}\right.$ cells/well in $200 \mu 1$ medium) at a final concentration of $5 \mu \mathrm{M}$, and the plates were incubated at $37^{\circ} \mathrm{C}$ for $1 \mathrm{~h}$. The fluorescence intensity was measured using a fluorescence plate reader (Victor X3; Perkin-Elmer, Waltham, MA, USA) with excitation at $485 \mathrm{~nm}$ and emission at $530 \mathrm{~nm}$.

Caspase-3 activity assay. The activity of caspase-3 was determined using a fluorometric method using the synthetic caspase-3 substrate Ac-DEVD-AFC. Briefly, $\mathrm{AC}$ extract-treated or -untreated cells were incubated for $24 \mathrm{~h}$ and then harvested by centrifugation. Cell pellets were re-suspended in cold lysis buffer $(0.5 \%$ Triton $\mathrm{X}-100,10 \mathrm{mM}$ EDTA, $10 \mathrm{mM}$ Tris-HCl, $\mathrm{pH}$ 7.5) and placed on ice for $15 \mathrm{~min}$. The cell lysates were then collected and incubated with caspase- 3 assay buffer (10\% glycerol, $2 \mathrm{mM}$ dithiothreitol, $20 \mathrm{mM}$ 4-(2-hydroxyethyl)-1-piperazineethanesulfonic acid, $\mathrm{pH}$ 7.5) and caspase-3 substrate DEVD-AFC for $1 \mathrm{~h}$ at $37^{\circ} \mathrm{C}$. Active caspase- 3 was measured by changes in the fluorescence at 485 and $535 \mathrm{~nm}$ using a microplate reader (Victor X3).

$R N A$ isolation and reverse transcription quantitative (RT-q) $P C R$. Total RNA was extracted using TRIzol after the HL60 cells had been treated with AC extract $(0,1,5,10$ or $20 \mu \mathrm{g} / \mathrm{ml})$ for $24 \mathrm{~h}$. Next, $2 \mu \mathrm{g}$ RNA from each sample was used to generate cDNA using the Omniscript RT kit (Qiagen) according to the manufacturer's instructions. The cycling conditions included a denaturation step at $95^{\circ} \mathrm{C}$ for $5 \mathrm{~min}$, followed by $30-35$ cycles of $95^{\circ} \mathrm{C}$ for $30 \mathrm{sec}, 55-60^{\circ} \mathrm{C}$ for $30 \mathrm{sec}$ and $72^{\circ} \mathrm{C}$ for $1 \mathrm{~min}$, and a final extension step at $72^{\circ} \mathrm{C}$ for $10 \mathrm{~min}$. The resulting total cDNA was then used to determine the expression levels of caspase-3, caspase-9, Bax, Bcl- $\mathrm{X}_{\mathrm{L}}$, Bcl-2 and cytochrome C. Equal amounts of PCR products were electrophoresed on $1.2 \%$ agarose gels (Bioneer Corp.) and visualized by RedSafe (iNtRON Biotechnology, Seoul, Korea) staining. Images of the gels were captured under ultraviolet light. Expression levels of GAPDH were used as internal control for the integrity of the mRNA. The primer sequences were as follows: Caspase-3 forward, 5'-ACATGGCGTGTCATAAAATACC-3' and reverse, 5'-CACAAAGCGACTGGATGAAC-3'; caspase-9 forward, 5'-ATGGACGAAGCGGATCGGCGGCTCC-3' and reverse, 5'-GCACCACTGGGGGTAAGGTTTTCTAG-3'; Bax forward, 5'-GTGCACCAAGGTGCCGGAAC-3' and reverse, 5'-TCAGCCCATCTTCTTCCAGA-3'; Bcl-XL forward, 5'-CCCAGAAAGGATACAGCTGG-3' and reverse, 5'-GCGATCCGACTCACCAATAC-3'; Bcl-2 forward, 5'-GTGAACTGGGGGAGGATTGT-3' and reverse, 5'-GGAGAAATCAAACAGAGGCC-3'; cytochrome C forward, 5'-CTACGGACACCTCAGGCAGT-3' and reverse, 5'-GGTGTGGTCCAAGGAAGAGA-3'; and GAPDH forward, 5'-CAAAAGGGTCATCATCTCTG-3' and reverse, 5'-CCTGCTTCACCACCTTCTTG-3'.

Protein extraction and western blot analysis. Following treatment with AC extract for 24 h, HL60 cells were harvested, washed with ice-cold PBS and lysed in lysis buffer containing a protease-inhibitor-cocktail tablet (Roche Diagnostics, Basel, Switzerland). The supernatant was obtained by centrifuging at 2,000 x g for $15 \mathrm{~min}$. Total protein was extracted and protein concentration was determined using a bicinchoninic acid assay kit (Thermo Fisher Scientific). For immunoblotting, $30 \mu \mathrm{g}$ protein from each sample was subjected to $10 \%$ SDS-PAGE and separated proteins were transferred onto a PVDF membrane. The membrane was blocked with 5\% skimmed milk at room temperature for $1 \mathrm{~h}$ and then incubated with the primary antibodies against caspase-3 (cat.

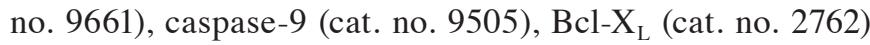
(1:1,000; Cell Signaling Technology, Danvers, MA, USA), PARP (cat. no. ab194217) (1:1,000; Abcam, Cambridge, MA, USA), phosphorylated (p)-JNK (cat. no. sc-6254), p-ERK (cat. no. sc-7383), p-p38 (cat. no. sc-7973) (1:1,000; Santa Cruz Biotechnology, Inc.) and GAPDH (cat. no. sc-32233) 
$\mathbf{A}$

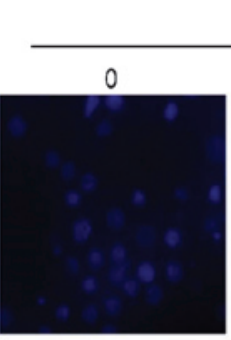

C

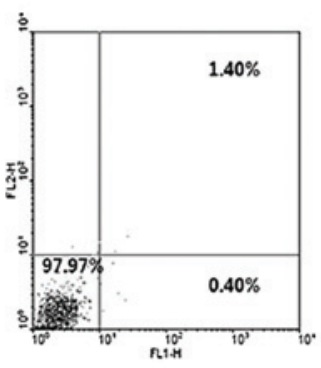

0
$\mathrm{AC}(\mu \mathrm{g} / \mathrm{ml})$
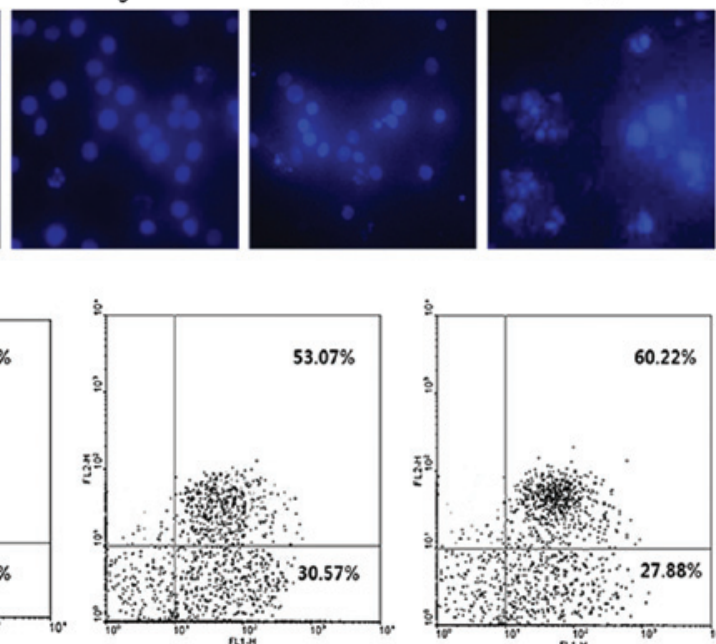

10

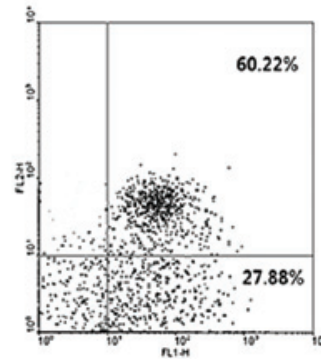

20
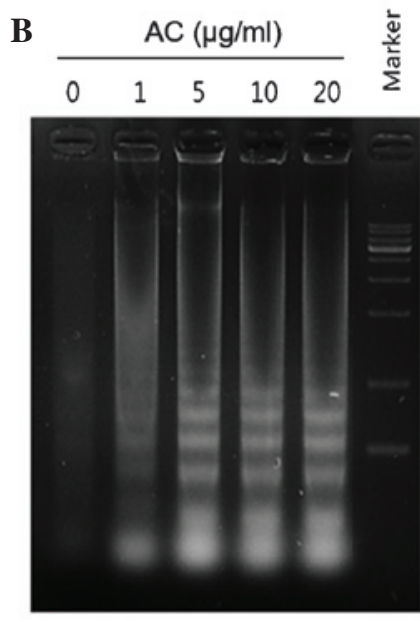

$\mathrm{AC}(\mu \mathrm{g} / \mathrm{ml})$

Figure 2. Induction of apoptosis by AC extract in human leukemia HL60 cells. (A) Images of Hoechst 33342-stained nuclei were captured with a fluorescent microscope using a blue filter (magnification, x400). (B) HL60 cells exposed to AC extract at various concentration were analyzed for DNA fragmentation. The genomic DNA subjected to $1.5 \%$ agarose gel electrophoresis and visualized under ultraviolet light after staining. (C) Flow cytometric analysis of AC-induced apoptosis and post-apoptotic necrosis in HL60 cells using Annexin V-fluorescein isothiocyanate/propidium iodide double staining. AC, Azorella compacta.
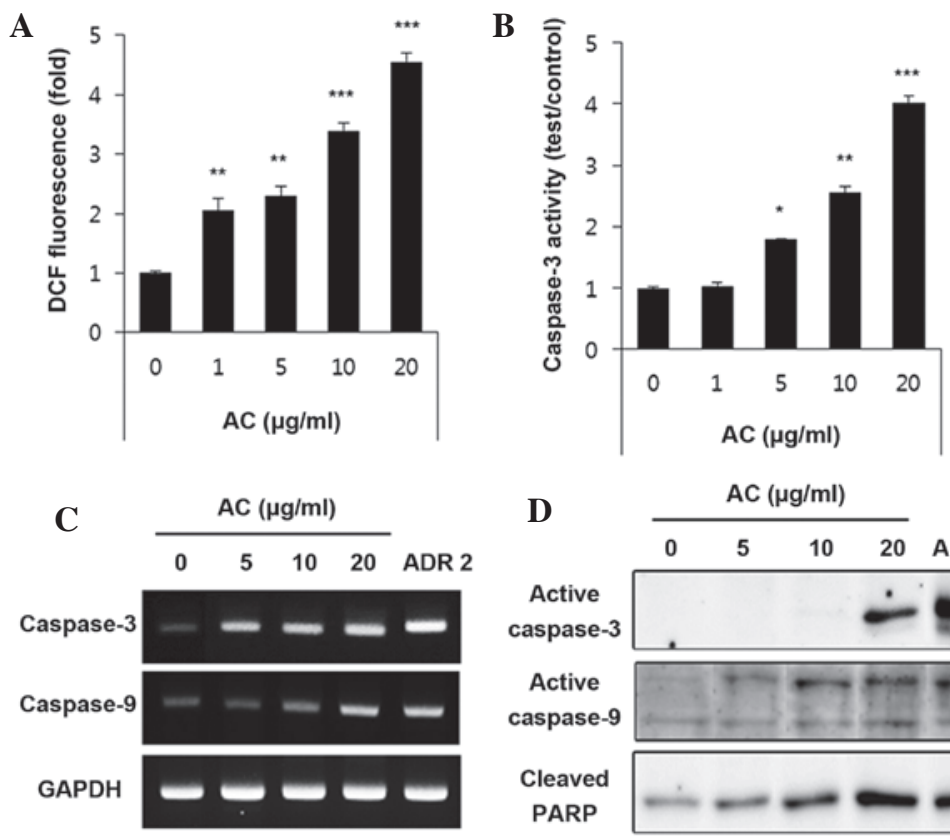

$\mathbf{D}$
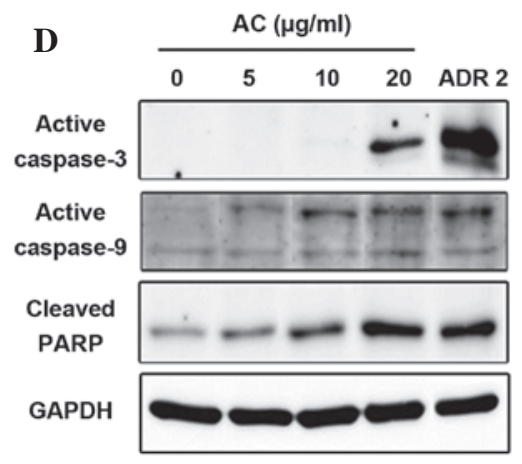

Figure 3. AC extract increases gene expression of caspase-3 and -9 in HL60 cells in a dose-dependent manner. (A) Production of ROS in HL60 cells treated with AC extract. The production of ROS was determined fluorometrically by the DCFH-DA assay. (B) Caspase-3 activity were determined using caspase-3 substrate Ac-DEVD-AFC. Values are expressed as a percentage of the vehicle-treated control \pm standard deviation of three separate experiments. "P<0.05; ${ }^{* *} \mathrm{P}<0.01 ;{ }^{* * *} \mathrm{P}<0.001$ vs. control. (C) The expression of mRNA was assessed using reverse transcription quantitative polymerase chain reaction analysis. (D) Western blot analysis of active caspase-3 and -9 as well as cleaved PARP. GAPDH was used as an internal control. PARP, poly(adenosine diphosphate ribose) polymerase; ROS, reactive oxygen species; ADR, adriamycin; AC, Azorella compacta.

(1:2,000; Santa Cruz Biotechnology, Inc.), respectively, at $4^{\circ} \mathrm{C}$ overnight. After washing, the membrane was incubated with anti-rabbit (cat. no. sc-2030) or anti-mouse (cat. no. sc-2005) secondary antibody (1:2,000; Santa Cruz Biotechnology,
Inc.). GAPDH was used as an internal control to monitor equal protein loading and transfer of proteins from the gel to the membranes; for this, blots were stripped with GAPDH antibody. Signals were detected using an enhanced ECL 
A

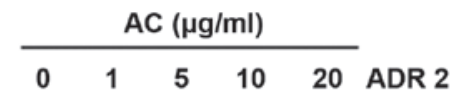

Bcl-2

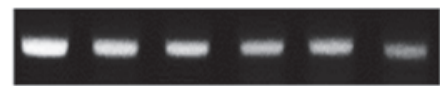

Bcl-X

Bax

Cyto c

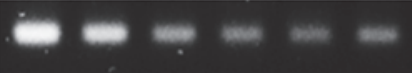

GAPDH

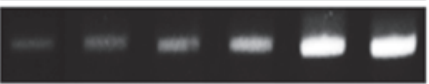

B

\begin{tabular}{llllll}
\multicolumn{4}{c}{ AC $(\mu \mathrm{g} / \mathrm{ml})$} \\
\cline { 1 - 4 } & 1 & 5 & 10 & 20 & ADR 2
\end{tabular}

Bcl-2

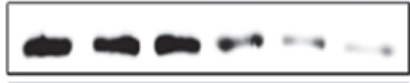

Bcl-X

Bax
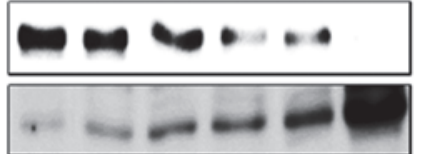

Cyto c

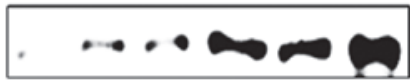

GAPDH

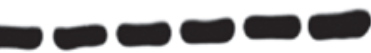

Figure 4. Expression levels of apoptosis-associated genes following AC extract treatment in human leukemia HL60 cells. Cells were seeded at 3x105 cells $/ \mathrm{ml}$ and treated with the indicated concentrations of AC extract for $24 \mathrm{~h}$. (A) The expression of mRNA was analyzed by reverse transcription quantitative polymerase chain reaction analysis. (B) Western blot analysis of Bcl-2, Bcl-Xl, Bax and cytochrome $c$. GAPDH was used as an internal control. AC, Azorella compacta; Bcl-2, B-cell lymphoma 2; Bcl-Xl, Bcl extra large protein; Bax, Bcl-2-associated X protein; Cyto, cytochrome; ADR, adriamycin.
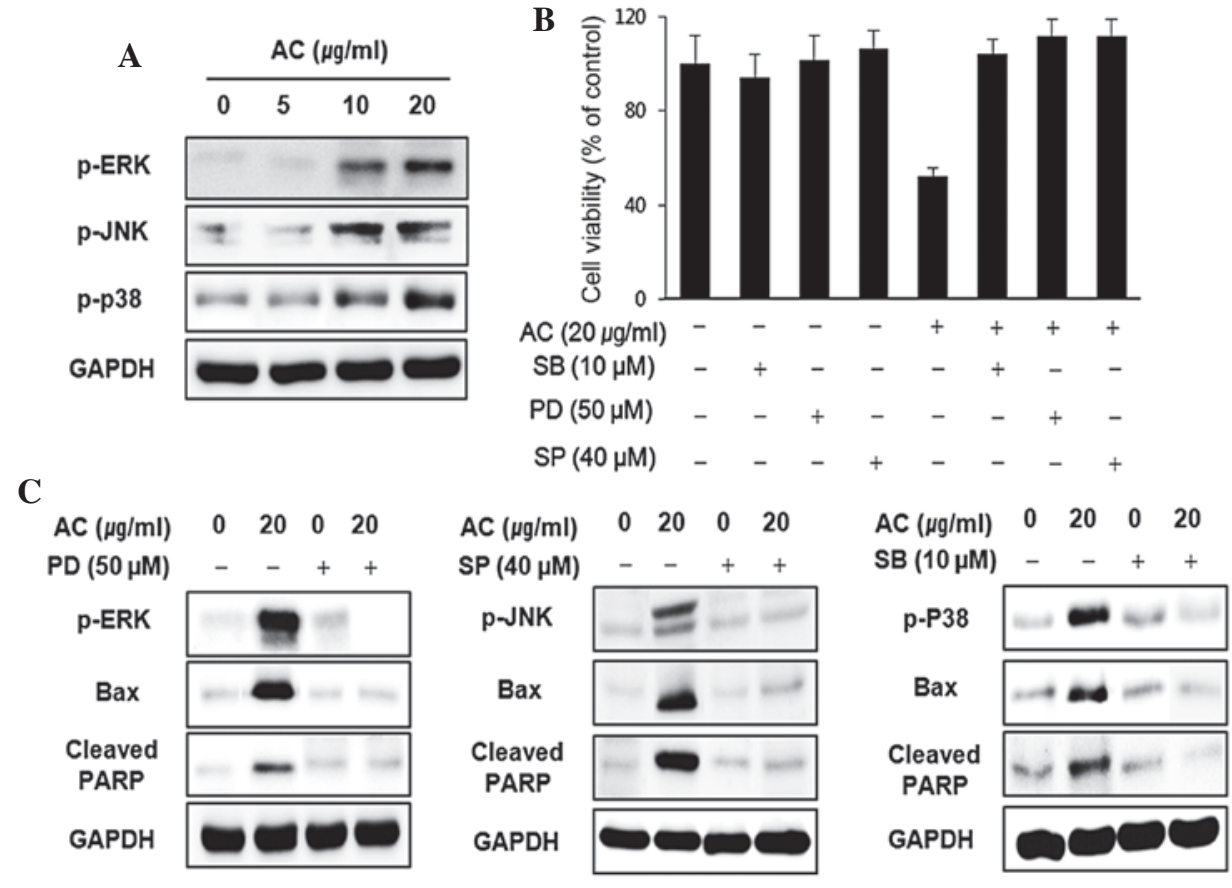

Figure 5. MAPKs were involved in AC extract-induced apoptosis of HL60 cells. (A) HL60 cells were treated with AC extract at indicated concentrations for $24 \mathrm{~h}$, and the activation of MAPKs family proteins was determined by western blotting. (B) Cells pre-treated with SP600125 (40 $\mu \mathrm{M}), \mathrm{SB} 203580(10 \mu \mathrm{M})$ or PD98059 $(50 \mu \mathrm{M})$ for $1 \mathrm{~h}$ were incubated with AC extract for $24 \mathrm{~h}$ and cell viability was assessed using an MTT assay. (C) The effects of AC and/or SP600125, SB203580 and PD98059 on the activation of MAPK family proteins PARP and Bax were determined by western blot analysis. MAPK, mitogen-activated protein kinase; p-ERK, phosphorylated extracellular signal-regulated protein kinase; JNK, c-Jun N-terminal kinase; Bax, B-cell lymphoma 2-associated X protein; ARP, poly(adenosine diphosphate ribose) polymerase; PD, ERK inhibitor PD98059; SP, JNK inhibitor SP600125; SB, p38 inhibitor SB203580; AC, Azorella compacta.

reagent, and an LAS 4000 imaging system (Fujifilm, Tokyo, Japan). The results shown are representative of three independent experiments.

Statistical analysis. All in vitro experiments were performed in triplicate, and each data point represents the average of at least three independent experiments. Values are expressed as the mean \pm standard deviation. The comparisons were made between controls and treated cultures using an unpaired Student's $t$-test. $\mathrm{P}<0.05$ was considered to indicate a statistically significant difference between values.

\section{Results}

AC extract inhibits cell growth and induces apoptosis in human leukemic HL60 cells. To determine the effects of AC extract on the growth of cancer cells, HepG2, SNU-1, MCF7, HT1080, A549 and HL60 cells were treated with AC extract at concentrations of $1-100 \mu \mathrm{g} / \mathrm{ml}$ for $24 \mathrm{~h}$, after which cell proliferation was assessed by MTT assay. AC extract inhibited the growth of HL60 cells in a dose-dependent manner (Fig. 1). At concentrations of $40 \mu \mathrm{g} / \mathrm{ml}$ and higher, AC extract almost completely inhibited the growth of HL60 cells. The $\mathrm{IC}_{50}$ of AC 
extract was determined to be $34 \pm 4.06 \mu \mathrm{g} / \mathrm{ml}$ on HL60 cells. Next, the present study investigated whether the observed inhibitory effects of AC extract on cell viability resulted from apoptotic cell death. Apoptosis is a process of programmed cell death, which is characterized by various biochemical and morphological changes. To evaluate the effects of $\mathrm{AC}$ extract on nuclear morphology, Hoechst 33342 staining was performed. The nuclei of cells treated with AC extract at 5, 10 and $20 \mu \mathrm{g} / \mathrm{ml}$ were deeply stained and exhibited bright fluorescence, which indicated the condensation of chromatin (Fig. 2A). In addition, as shown in Fig. 2B, DNA ladder formation was confirmed by agarose gel electrophoresis. Efficient DNA laddering was observed in HL60 cells treated with $>10 \mu \mathrm{g} / \mathrm{ml}$ AC extract for $24 \mathrm{~h}$. With increasing concentration, a more intense pattern of DNA laddering was detected (Fig. 2B). The apoptosis-inducing effects of the AC extract were also evaluated using Annexin V/PI staining. As show in in Fig. 2C, the apoptotic rate increased in an AC concentration-dependent manner. The early and late apoptotic fractions in control cells were 0.40 and $1.40 \%$, respectively, but increased to 23.80 and $58.82 \%$ after treatment with $20 \mu \mathrm{g} / \mathrm{ml} \mathrm{AC}$ extract (Fig. 2C). PI-positive cells also increased marginally at higher AC concentrations.

AC extract induces ROS production and activation of caspases in human leukemic HL60 cells. ROS levels in AC-extract-treated HL60 cells were quantified $1 \mathrm{~h}$ after the addition of DCFH-DA. As displayed in Fig. 3A, intracellular ROS levels significantly increased in an AC concentration-dependent manner. These results suggested that ROS production may be the cause of AC extract-induced apoptosis in HL60 cells. As AC-extract treatment led to enhanced ROS generation, it is possible that alterations in the cell may have a role in AC extract-induced apoptosis. Caspase-3 and -9 , known to serve as important mediators of intrinsic apoptotic pathways, also contribute to general apoptotic morphology through the cleavage of various cellular substrates, including PARP (21). As indicated in Fig. 3B, western blot analysis showed that AC extract induced the activation of caspase- 3 in a concentration-dependent manner. RT-PCR was used to detect the mRNA expression of caspase- 3 and caspase-9 $24 \mathrm{~h}$ after AC-extract treatment. The change in mRNA expression was normalized against GAPDH expression. Fig. 3C shows that the mRNA expression of caspase- 3 and caspase- 9 increased in a manner that was AC-extract dose-dependent. Furthermore, the western blots in Fig. $3 \mathrm{D}$ showed that AC-extract treatment induced the activation of caspase- 3 and -9 in a concentration-dependent manner. In addition, western blot analysis revealed that progressive proteolytic cleavage products of PARP protein, a downstream target of activated caspase-3, occurred in HL60 cells treated with AC extract.

AC extract activates apoptosis-associated signaling in human leukemia HL60 cells. The underlying mechanism by which AC extract induced apoptosis of HL60 cells was delineated by RT-PCR and western blot analyses. As shown Fig. 4A and B, examination of $\mathrm{Bax}, \mathrm{Bcl}-2, \mathrm{Bcl}-\mathrm{X}_{\mathrm{L}}$ and cytochrome $\mathrm{C}$ expression during apoptosis indicated that $\mathrm{AC}$ treatment at 1, 5, 10, or $20 \mu \mathrm{g} / \mathrm{ml}$ dose-dependently increased the expression of cytochrome $\mathrm{C}$ and pro-apoptotic Bax, whereas the expression of anti-apoptotic Bcl-2 and Bcl- $\mathrm{X}_{\mathrm{L}}$ was downregulated with increasing concentrations of $\mathrm{AC}$ extract.

Activation of MAPK is involved in AC-extract-induced apoptosis in human leukemia HL60 cells. Next, the effect of AC-extract treatment on the expression and activities of MAPKs was investigated in order to determine whether these signaling pathways have a role in mediating the observed apoptotic response. To confirm an association between the activation of MAPKs and the induction of apoptosis by the AC extract, the cells were pre-treated with MAPK inhibitors and their viability was assessed using an MTT assay. As shown in Fig. 5A, the levels of p-p38, p-ERK and p-JNK proteins increased in an AC concentration-dependent manner. As Fig. 5B demonstrates, pre-treatment with SB203580 (inhibitor of p38), PD98059 (inhibitor of ERK) and SP600125 (inhibitor of JNK) increased the viability of cells treated with AC extract. To further determine the mechanism of MAPKs activation in HL60 cells by AC extract, the effects of these MAPK inhibitors on the release of Bax and cleaved PARP proteins were also investigated (Fig. 5C). The results showed that MAPK inhibitor blocked pro-apoptotic protein and cleaved PARP protein. These results indicated that AC extract induced apoptosis via these two proteins of the intrinsic apoptotic pathway.

\section{Discussion}

The ability to induce tumor-cell apoptosis is an important property of candidate anti-cancer drugs and serves to discriminate between anti-cancer drugs and compounds with toxicity. Much effort has been directed toward identifying compounds that influence apoptosis and toward understanding their mechanisms of action. Extracts prepared from a large variety of plants have been demonstrated to possess the ability to trigger the activation of apoptotic pathways $(22,23)$. The mechanisms of apoptosis induction are complex and not fully known, but certain key events have been identified, which appear essential for the cell to enter apoptosis (24). The notion that apoptosis represents a critical element in control of cell-number in physiological and pathological situations has been well reviewed and its role in oncogenesis is now well established (25). Apoptosis has an important function in the normal development and differentiation of multicellular organisms and is characterized by morphological and biological changes, including chromatin condensation, cytoplasmic shrinkage and DNA degradation (26). Apoptosis also serves as a critical protective mechanism against carcinogenesis caused by mutations of the genetic material in normal cells and against various other forms of carcinogenesis. A variety of stimuli can trigger apoptosis, including death receptor-mediated signaling (extrinsic pathway) or intracellular stresses (intrinsic pathway) (27). The present study aimed to determine the capacity of AC extract to induce apoptosis and to identify the associated biochemical mechanisms in human leukemic cells. The results demonstrated that AC extract inhibits leukemic cell growth by induction of apoptotic cell death, which appeared to account for its anti-proliferative action. Depending on the cell line, $\mathrm{AC}$ extract exerted growth-inhibitory effects on cancer cells with $\mathrm{IC}_{50}$-values of $20-100 \mu \mathrm{g} / \mathrm{ml}$ after $24 \mathrm{~h}$ treatment. In HL60 cells, a promising level of cytotoxicity was observed; 
therefore, the present study pursued the effect of AC extract on human leukemia HL60 cells. It was demonstrated that AC extract exerted a significant anti-proliferative effect against HL60 cells in a dose-dependent manner. Further cellular and biochemical analysis indicated that the proliferation of inhibitory activity of AC extract was associated with the induction of apoptosis. Several sensitive methods for detecting apoptosis have been developed. Staining of apoptotic cells with the fluorescent dye Hoechst 33342 is considered to be a suitable method for evaluating changed nuclear morphology (28). One of the earliest events indicating apoptosis is the loss of plasma membrane polarity, accompanied by translocation of PS from the inner to outer membrane leaflets, thereby exposing PS to the external environment. The phospholipid-binding protein Annexin V has a high affinity for PS and can bind to apoptotic cells with an inverted mitochondrial membrane; the quantity of fluorescently-labeled Annexin-V correlates with the loss of membrane polarity during apoptosis. The perforation and inversion of the mitochondrial membrane precedes the complete loss of membrane integrity that accompanies later stages of cell death, resulting from either apoptosis or necrosis. By contrast, PI only enters cells after loss of membrane integrity. Thus, dual staining with Annexin V and PI allows for a clear discrimination between affected cells, early apoptotic cells and late apoptotic or necrotic cells (29). HL60 cells treated with AC extract at lower concentrations contained a population of Annexin V-positive cells indicating early apoptosis, while Annexin V-and PI-positive cells were present at higher AC concentrations, which revealed the occurrence of post-apoptotic necrosis. The impairment of mitochondrial function has been considered to be a key event in the ROS-mediated apoptotic pathway (30). In the present study ROS generation was indicated to be involved in AC extract-induced cell death. ROS levels were determined in HL60 cells after AC-extract treatment using the peroxide-sensitive fluorescent probe, DCFH-DA, and a four-fold increase was evidenced after $24 \mathrm{~h}$. In general, the mitochondria-mediated intrinsic pathway and the death-receptor-triggered extrinsic pathway can lead to caspase-3 activation (31). In the system of the present study, caspase-9 was significantly activated, which implicated mitochondrial involvement, since caspase-9 is the initiator caspase for the intrinsic apoptotic pathway (32). In the intrinsic pathway, the ratio of the expression of pro-apoptotic proteins such as Bax and anti-apoptotic proteins, including Bcl-2 and $\mathrm{Bcl}-\mathrm{X}_{\mathrm{L}}$, ultimately determines cell death or survival through regulation of mitochondrial-permeability transition. This leads to activation of caspase- 3 for induction of apoptosis via release of cytochrome $\mathrm{C}$ to the cytosol (11). The results of the present study indicated that AC extract induced Bax translocation from the cytosol to the mitochondria, leading to the release of cytochrome $\mathrm{C}$, apoptosome formation, and finally, induction of apoptosis in HL60 cells.

MAPKs, including ERK, JNK and p38, have critical roles in cell survival and apoptosis in various types of cancer cell. It is known that activation of ERK, JNK and p38 leads to induction of apoptosis $(33,34)$. Activation of ERK, JNK and p38 can induce mitochondrial dysfunction with subsequent release of apoptotic proteins, such as cytochrome $\mathrm{C}$, from the mitochondria into the cytosol, and finally activate caspase- 9 and caspase- 3 . In the present study, treatment with
AC extract resulted in upregulation of ERK, JNK and p38 phosphorylation. Therefore, the involvement of ERK, JNK, and p38 activation in the MAPK-signaling pathway during AC-extract-induced apoptosis in HL60 cells was further investigated. As the results indicated, PD98059 (inhibitor of ERK), SP600125 (inhibitor of JNK) and SB203580 (inhibitor of p38) blocked AC-extract-induced apoptosis of HL60 cells by inhibiting the interaction between Bax and activated PARP. The results therefore suggested an association of AC-extract-induced apoptosis with activation of ERK, JNK and $\mathrm{p} 38 / \mathrm{MAPK}$.

In conclusion, the present study demonstrated that $\mathrm{AC}$ extract significantly induced apoptosis in leukemia cells by increasing the generation of ROS, by causing translocation of Bax to the mitochondria from the cytosol, and by initiating the release of cytochrome $\mathrm{C}$ followed by activation of caspase- 9 and caspase-3. AC extract was found to exert its anti-cancer effects via the ERK, JNK and p38/MAPK-mediated intrinsic apoptotic pathway in human leukemia HL60 cells. Future studies will examine the effects of AC on upstream signaling pathways of MAPKs and evaluate its anti-cancer efficacy in vivo using nude mouse models. As the present study did not observe any side effects, $\mathrm{AC}$ is expected to be a promising anti-cancer drug. The potential use of $\mathrm{AC}$ in combination with other drugs may also be investigated.

\section{Acknowledgements}

This study was supported by the Ministry of Science, ICT and Future Planning (no. FGC1011433) and the KRIBB Initiative Program (no. KGM1221521) of the Republic of Korea. The authors would like to thank the International Biological Material Research Center (Korea Research Institute of Bioscience and Biotechnology, Daejeon, Korea) for providing the AC extract.

\section{References}

1. Danial NN and Korsmeyer SJ: Cell death: critical control points. Cell 116: 205-219, 2004

2. Wyllie AH, Kerr JF and Currie AR: Cell death: the significance of apoptosis. Int Rev Cytol 68: 251-306, 1980.

3. Earnshaw WC: Nuclear changes in apoptosis. Curr Opin Cell Biol 7: 337-343, 1995.

4. Nagata S: Apoptosis by death factor. Cell 88: 355-365, 1997.

5. Green DR and Reed JC: Mitochondria and apoptosis. Science 281: 1309-1312, 1998

6. Kaufmann SH and Earnshaw WC: Induction of apoptosis by cancer chemotherapy. Exp Cell Res 256: 42-49, 2000.

7. Jin Z and El-Deiry WS: Overview of cell death signaling pathways. Cancer Biol Ther 4: 139-163, 2005.

8. Kroemer G and Reed JC: Mitochondrial control of cell death. Nat Med 6: 513-519, 2000.

9. Lazebnik YA, Kaufmann SH, Desnoyers S, Poirier GG and Earnshaw WC: Cleavage of poly (ADP-ribose) polymerase by a proteinase with properties like ICE. Nature 371: 346-347, 1994.

10. Adams JM and Cory S: The Bcl-2 protein family: arbiters of cell survival. Science 281: 1322-1326, 1998.

11. Li H, Zhu H, Xu CJ and Yuan J: Cleavage of BID by caspase 8 mediates the mitochondrial damage in the Fas pathway of apoptosis. Cell 94: 491-501, 1998.

12. Kyosseva SV: Mitogen-activated protein kinase signaling. Int Rev Neurobiol 59: 201-220, 2004.

13. Keshet Y and Seger R: The MAP kinase signaling cascades: a system of hundreds of components regulates a diverse array of physiological functions. Methods Mol Biol 661: 3-38, 2010. 
14. Sumbayev VV and Yasinska IM: Regulation of MAP kinase-dependent apoptotic pathway: implication of reactive oxygen and nitrogen species. Arch Biochem Biophys 436: 406-412, 2005.

15. Loyola LA, Bórquez J, Morales G, San-Martín A, Darias J, Flores $\mathrm{N}$ and Giménez A: Mulinane-type diterpenoids from Azorella compacta display antiplasmodial activity. Phytochemistry 65: 1931-1935, 2004.

16. Wachter GA, Franzblau SG, Montenegro G, Suarez E, Fortunato RH, Saavedra E and Timmermann BN: A new antitubercular mulinane diterpenoid from Azorella madreporica Clos. J Nat Prod 61: 965-968, 1998.

17. Areche C, Rojas-Alvarez F, Campos-Briones C, Lima C, Pérez EG and Sepúlveda B: Further mulinane diterpenoids from Azorella compacta. J Pharm Pharmacol 65: 1231-1238, 2013.

18. Wachter GA, Matooq G, Hoffmann JJ, Maiese WM, Singh MP, Montenegro G and Timmermann BN: Antibacterial diterpenoid acids from Azorella compacta. J Nat Prod 62: 1319-1321, 1999.

19. Fuentes NL, Sagua H, Morales G, Borquez J, San Martin A, Soto J and Loyola LA: Experimental antihyperglycemic effect of diterpenoids of llareta Azorella compacta (Umbelliferae) Phil in rats. Phytother Res 19: 713-716, 2005

20. Lee K, Kwon OK, Xia Y and Ahn KS: Effect of AC-264, a novel indole derivative, on apoptosis in HL-60 cells. Bull Korean Chem Soc 31: 3777-3781, 2010.

21. Pink JJ, Wuerzberger-Davies S, Tagliarino C, Planchon SM, Yang X, Froelich CJ and Boothman DA: Activation of a cysteine protease in MCF-7 and T47D breastcancer cells during beta-lapachone-mediated apoptosis. Exp Cell Res 255: 144-155, 2000.

22. Ren G, Zhao YP, Yang L and Fu CX: Anti-proliferative effect of clitocine from the mushroom Leucopaxillus giganteus on human cervical cancer HeLa cells by inducing apoptosis. Cancer Lett 262: 190-200, 2008.

23. Wu SJ, Ng LT, Chen CH, Lin DL, Wang SS and Lin CC: Antihepatoma activity of Physalis angulata and $P$. peruviana extracts and their effects on apoptosis in human Hep G2 cells Life Sci 74: 2061-2073, 2004.
24. Andersson B, Janson V, Behnam-Motlagh P, Henriksson R and Grankvist K: Induction of apoptosis by intracellular potassium ion depletion: Using the fluorescent dye PBFI in a 96-well plate method in cultured lung cancer cells. Toxicol In vitro 20: 986-994, 2006.

25. Hall PA: Assessing apoptosis: A critical survey. Endocr Relat Cancer 6: 3-8, 1999.

26. Hengartner MO: The biochemistry of apoptosis. Nature 407: 770-776, 2000.

27. Galluzzi L, Larochette N, Zamzami N and Kroemer G: Mitochondria as therapeutic targets for cancer chemotherapy. Oncogene 25: 4812-4830, 2006.

28. Belloc F, Dumain P, Boisseau MR, Jalloustre C, et al: A flow cytometric method using Hoechst 33342 and propidium iodide for simultaneous cell cycle analysis and apoptosis determination in unfixed cells. Cytometry 17: 59-65, 1994.

29. Yang L, Wu S, Zhang Q, Liu $F$ and Wu P: 23,24-Dihydrocucurbitacin B induces G2/M cell-cycle arrest and mitochondria-dependent apoptosis in human breast cancer cells (Bcap37). Cancer Lett 256: 267-278, 2007.

30. Wang R, Li C, Song D, Zhao G, Zhao L and Jing Y: Ethacrynic acid butyl-ester induces apoptosis in leukemia cells through a hydrogen peroxide mediated pathway independent of glutathione S-transferase P1-1 inhibition. Cancer Res 67: 7856-7864, 2007.

31. Cullen SP and Martin SJ: Caspase activation pathways: Some recent progress. Cell Death Differ 16: 935-938, 2009.

32. Zheng TS, Hunot S, Kuida K, Momoi T, Srinivasan A, Nicholson DW, Lazebnik Y and Flavell RA: Deficiency in caspase-9 or caspase-3 induces compensatory caspase activation. Nat Med 6: 1241-1247, 2000.

33. Moon DO, Kim MO, Choi YH, Kim ND, Chang JH and Kim GY: Bcl-2 overexpression attenuates SP600125-induced apoptosis in human leukemia U937 cells. Cancer Lett 264: 316-325, 2008

34. Cross TG, Scheel-Toellner D, Henriquez NV, Deacon E, Salmon M and Lord JM: Serine/threonine protein kinases and apoptosis. Exp Cell Res 256: 34-41, 2000. 